\title{
EVIDENCE BASED LEARNING: AN ANALYSIS OF IMPACT OF EXPERIENTIAL LEARNING ON ATTAINMENT OF INTENDED SPECIFIC LEARNING OUTCOME
}

\author{
Prashant Thote ${ }^{*} \bowtie$, Gowri. S 2 \\ *1, 2 Gyanodaya Vidya Mandir, India
}

DOI: https://doi.org/10.29121/granthaalayah.v9.i1.2021.2971

Article Type: Research Article

Article Citation: Prashant Thote, and Gowri. S. (2021). EVIDENCE

BASED LEARNING: AN ANALYSIS

OF IMPACT OF EXPERIENTIAL

LEARNING ON ATTAINMENT OF

INTENDED SPECIFIC LEARNING

OUTCOME. International Journal of

Research -GRANTHAALAYAH, 9(1),

66-74.

https://doi.org/10.29121/granthaa

layah.v9.11.2021.2971

Received Date: 25 December 2020

Accepted Date: 25 January 2021

Keywords:

Specific Learning Outcomes

Corrosion

Rusting

Electrode Potential

Galvanic Cell

\section{ABSTRACT}

The intension of the present study is to enhance the conceptual understanding amongst Grade 12 School students. As a teacher, it is very challenging to make the learners to be strong and have deep understanding in the theoretical concept for its application in day- to-day life. The experiential learning activities enhance the deep learning. The purpose of the study is to investigate the effect of experiential learning activities designed for the concept "corrosion" on the academic performance amongst Senior Secondary School students in Chemistry. Totally 40 students participate in the study. The samples are drawn using Purposive sampling technique. The samples are divided in to two groups: study and the control group based of their performance of formative assessment before the treatment. Students of the study group are taught by using experiential learning activities. The present study is experimental in nature. Data is collected using formative assessment before and after the treatment. Mean, mean difference and standard deviation are the statistical tools applied to analyze the data. Results of the study reveal that experiential learning activities have a positive impact on the deep conceptual understanding to achieve the intended specific learning outcome. Based on the results few recommendations are made.

\section{INTRODUCTION}

"Thoughts and learning's are small values unless translate in to action" - Unknown

The word "Science" is the derivative of Latin word "scientia" - means knowledge. Science is an organized enterprise that constructs and organizes knowledge from the tested explanations and predictions. Chemical education is an inclusive term that refers the process of teaching learning in Chemistry at educational institutions. Chemical education is facing many challenges in the $21^{\text {st }}$ century at Senior Secondary School level and these challenges can be overcome very easily. It requires comprehensive effort to measure the conceptual knowledge of Chemistry. The concepts are formed when ideas and thoughts are developed based on the common properties of the object and process of observation. The conceptual difficulties are common amongst learners at an intermediate level. Student's difficulty in understanding the concepts in Chemistry is the major problem of concern not only for the teachers but also for the students. The unit electrochemistry is considered as the most difficulty unit in Grade 12 .

(C) 2021 The Author(s). This is an open access article distributed under the terms of the Creative Commons Attribution License, which permits unrestricted use, distribution, and reproduction in any medium, provided the original author and source are credited. 
As a teacher I strongly believe that my classroom instructions should not only give joyful experience but also be valuable for life. Students should not lose interest in classroom instructions at any interval of time. Chemistry is always lovable for me and must be for my students also. Science teaching is activity based and aims to encourage students to explore and observe their environment. It is the responsibility of a teacher to nurture positive attitude towards Science subject. As a teacher I take learning seriously. It does not mean that learning must be a serious activity for the learners. Joyful learning experiences are improved by encouragement and motivation to achieve the intended learning outcome.

The students are taught "Electro Chemistry" unit in the academic session 2020-21 on online mode. The formative assessment is conducted to assess student's acquisition of specific learning outcomes. Students face difficulties in understanding the following concepts:

1) Conduction of electrolysis ions.

2) Redox reaction.

3) Mechanism of electrolysis and its practical application.

4) Oxidizing and reducing agent.

5) Product obtained at anode and cathode

6) Concept of corrosion and rusting.

The remedial measures are initiated to foster the conceptual understanding to acquire intended specific learning outcomes. In this paper only remedial measure and its application for the conceptual understanding of the concepts of rusting and corrosion are discussed.

\subsection{CONCEPT OF RUSTING}

When metals are wide-open to air or kept open for some time, the metal surfaces are slowly eaten or corroded. It is the formation of rust on the compounds like: Sulphides, Oxides and Carbonates due to the gases and vapors present in the air and because of the nature of metals. Such metals are known as corrode metals. Metals like gold and platinum are called as noble metals as they are not affected by corrosion. Hence corrosion is slow eating of metals caused by the vapours of water present in the air and by certain chemical compounds. If iron metal is involved the process is called corrosion. Rust is a red iron oxide and is formed by red oxidation in presence of moisture or wonder. Rust contains hydrated iron (III) oxide Fe2O3 x H2O and Iron (III) oxide FeO (H2O), Fe (OH)3. In soil most commonly found corrosion products are goethite and magnetite. Model for corrosion of iron in soil is developed. The model includes anode reaction of iron oxidation to ferrous iron and the reaction at cathode of oxygen to hydroxide iron.

Rust is the slow decomposition or erosion of metal into other chemicals due to reaction of oxygen molecule. Air and water are both essential for the generation of rust. Rust is in reddish brown colour and is flakey because of the iron oxide formation on iron/ steel by the process of oxidation in presence of moisture. Hence rusting is a chemical reaction that is caused due to the weakening of metal in the existence of moisture and oxygen. It is the chemical process that causes the metal to change their colour. Change in colour of the metal is the physical indicator of rusting.

\subsection{FACTORS THAT PROMOTE RUSTING}

Rusting is mostly caused by the following three factors:

- Process related

- Packing related

- Environment related

\subsection{PROCESS RELATED}

The primary contributing factors for corrosion/rusting are the fabrication process, cold processing, heat treatment, mechanizing and handling process. 


\subsection{PACKING RELATED}

The packing material used such as non-treated paper and congregated paper hold moisture and fosters corrosion.

\subsection{ENVIRONMENT RELATED}

The contamination in air, weather elements such as humidity and temperature are the most common environmental elements that encourage corrosion. Iron is converted into native metal. The following are the environmental factors that stimulate corrosion:

- Humidity in air.

- Marine water (salty), distilled and fresh water.

- Industrial and urban atmosphere.

- Gases like chlorines and gases.

- Ammonia

- Hydrogen Sulphide.

- Oxides of Nitrogen and sulphur oxide.

- Fuel gases.

- Acids

- Alkalis.

- Soils.

Table 1: Alloy and Environmental factors that stimulate corrosion

\begin{tabular}{|c|c|c|}
\hline Sl.No & Materials & Factors \\
\hline 1 & All Alloys & Moisture and Chloride \\
\hline 2 & Magnesium Alloy & Mixture of Chloride, Chromate, Nitric Oxide, Flouride, Sodium Hydroxide and \\
moisture
\end{tabular}

From the above Table -1 it is very much clear that many factors are responsible for corrosion. The product manufacturing process and the packing of metals stimulate corrosion. Water contains ions that are aggressive and causes corrosion. At high humid temperature (that contains moisture and oxygen) and high $\mathrm{P}_{\mathrm{h}}$ (greater than 2) cannot protect metals but it also adversely affects staining, control of non-ferrous includes aluminum, brass, bronze and other factors includes sea water, alkalies, ammonia and soil.

Table 2: Types of rust

\begin{tabular}{|c|c|c|c|}
\hline Sl.No & Colour & Formula & Photos \\
\hline 1 & Red & Iron III oxide is formed due to high exposure to oxygen. & \\
& & &
\end{tabular}


Prashant Thote, and Gowri. S

\begin{tabular}{|c|c|c|c|}
\hline 2 & Yellow & Hydrated acids - Fe203H20, high oxygen water & \\
\hline 3 & Black & Iron (III) Oxide - high soluble & Ferrous \\
\hline 4 & Multiple & & \\
\hline 5 & Brown & Oxides Fe203 (High oxygen and low moisture) & \\
\hline
\end{tabular}

\subsection{APPROACH FOR REMEDIAL TEACHING}

The best approach for the class room instructions is to create interest among students towards learning. Students' academic achievement is adversely affected by the lack of teaching and learning resources, lack of competencies among teachers, poor infrastructure and prevalence of large gaps. Pupil centered activity based remedial teaching approaches are used to create interest among students.

The experiential learning activity design for conceptual understanding requires the following materials:

- Three labeled test tubes (A, B and C)

- Distilled boiled water

- Calcium chloride (anhydrous)

- Iron nails - 6 in numbers

- Cotton/wool

\subsection{PROCEDURE}

- Setup test tubes (A, B and C) as shown in the figure.

- Test tube A is filled with some quantity of Calcium Chloride (anhydroxide) and plug with cotton for some time to dry the air inside the test tube.

- Place cotton on the top of the Calcium Chloride and place two clean nails of iron on the top of the cotton in the dry test tube.

- Test tube is sealed. Leave it for four to five days.

- Fill the test tube B with distilled water and boil it for few minutes to drive off dissolved gases.

- Place two clean nails in the test tube quickly and use acid oil to seal the surface. Keep the test tube for three to four days.

- In test tube $\mathrm{C}$ add two pieces of nails and add water and keep it for three to four days.

\subsection{OBSERVATION}

- In test tube $\mathrm{C}$ nails are covered with reddish brown layer. It is because the nails are exposed to water and air. Reddish brown layer is the hydroxide iron (II), oxide $\left(\mathrm{Fe}_{2} \mathrm{O}_{3} \cdot 3 \mathrm{H}_{2} \mathrm{O}\right)$ or rust. 
- In test tube B no reddish layer of rust is observed as nails are not exposed to air and water.

- In test tube A nails are exposed to the dry air but no water and no rust is observed.

\subsection{CONCLUSION}

Not only air but water is also essential for rusting phenomena.

\subsection{STATEMENT OF THE PROBLEM}

The present paper is designed to explore the effect of experiential learning activities in Chemistry on academic performance of students. Hence the statement of the problem is "

\subsection{OBJECTIVES}

The objectives of the present paper are as follows:

- To explore the impact of experiential learning activities on academic performance in Chemistry among Senior Secondary School students.

- To suggest workable recommendations to enhance deep learning and to acquire specific learning outcomes.

\section{METHODS}

\subsection{HYPOTHESIS}

The following hypotheses are designed to achieve the objectives of the study:

H1: There is no significant difference between the study group and the control group on the formative assessment before treatment.

H2: There is no significant difference between the study group and the control group on the formative assessment after treatment.

H3: There is no significant difference between the study group and the control group on the formative assessment on retention test.

\subsection{POPULATION}

All the Senior Secondary students in the study area.

\subsection{SAMPLE}

Totally forty students of Grade 12 participate in the study. Sample students are divided into two groups: study and control group. Each group consists of twenty students.

\subsection{DELIMITATIONS OF THE STUDY}

The present study is restricted to:

- The students of only one co-educational school in the rural area.

- The students of Grade nine.

- Science subject. 


\subsection{RESEARCH DESIGN}

Experimental research design is employed for the present study. Formative assessment is conducted before and after the treatment. The following are the symbolic representations of the study

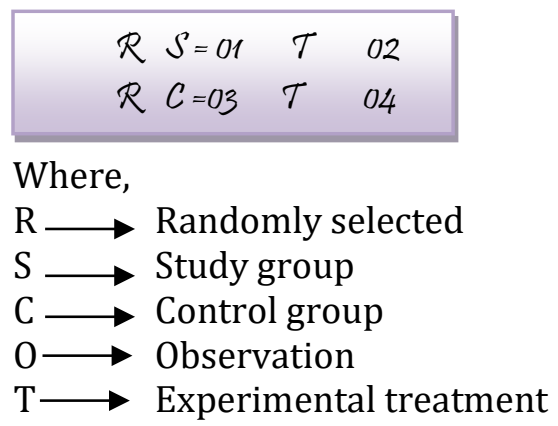

\subsection{TOOL}

The present study is experimental in nature. Formative assessment is conducted before and after the treatment (experiential learning activities). Data is collected for both the study group and the control group. Two formative assessments and one summative assessment is the tool for collecting the data.

\subsection{DATA COLLECTION}

Researcher administrated formative assessment before and after the experiential learning activities. Two formative assessments and one summative assessment is the tool for collecting the data.

\subsection{ANALYSIS OF DATA}

Data is collected from two formative assessments and one summative evaluation. Data is washed and presented in tabular form. Mean, mean difference and standard deviation are the statistical tools used for a analyzing the data. Significant mean difference between the mean score of both groups on variables of formative assessment before and after experiential learning activity and summative evaluation on retention score are tested at 0.05 level in applying t-test.

\section{RESULT AND DISCUSSIONS}

The objective of the present paper is to investigate the impact of experiential learning activities on the academic achievement of Senior Secondary school students in Chemistry. The present study is experimental in nature. The formative assessments before and after the experiential learning activity are administrated to collect data. Sample students are divided into two groups the study group and the control group. The students of the study group are taught the concept of rust and corrosion by using experiential learning activities for the period of one week. The formative assessment is conducted after the experiential learning activity. The summative evaluation is conducted as retention test at the end of the academic year. Data is gathered and compared. The entire statistical procedure is explained as under.

H1: There is no significant difference between the study group and the control group on the formative assessment before treatment.

Table 3: significant difference between mean score of formative assessment before the treatment

\begin{tabular}{|c|c|c|c|c|c|c|}
\hline Sl. No & N & Mean & SD & SE & t-Value & P-Value \\
\hline Study group & 20 & 43.98 & 2.98 & 0.80 & 0.051 & 0.97 \\
\hline Control group & 20 & 43.94 & 3.12 & & & \\
\hline
\end{tabular}

Non-significant $(\mathrm{p}>0.05) \mathrm{df}=38$

table value of $t$ at $0.05=2.02$ 


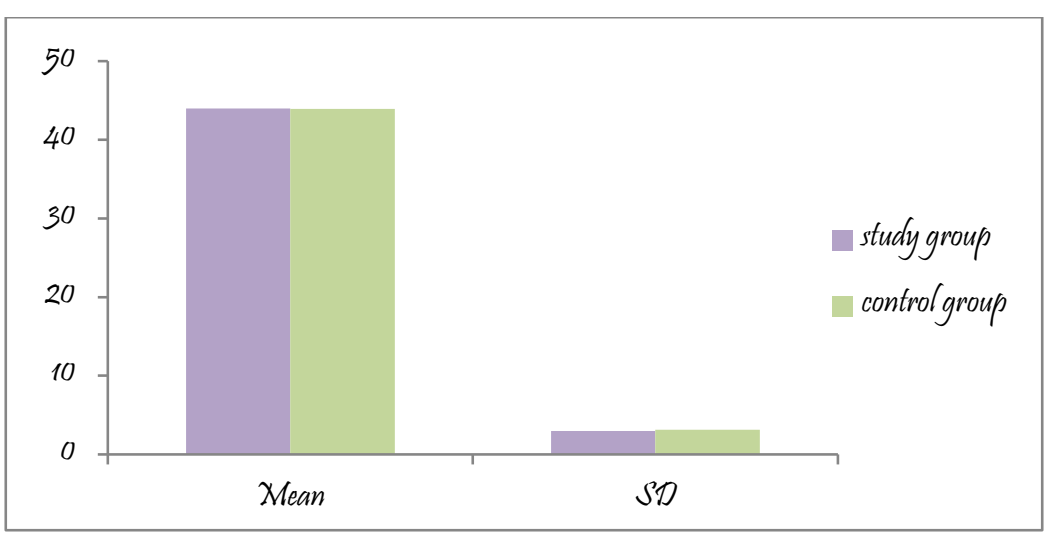

Figure 1: Mean difference between study and control group on formative assessment before the treatment.

Table- 3 depicts that the computed value of $t$ is found to be 0.001 and it is statistically non-significant. $t$-value is less than critical value of $t$ at 0.05 level. Hence null hypothesis "There is no significant difference between the study group and the control group on the formative assessment before treatment" is accepted. It unambiguously shows that students of both study and control group have similar performance in formative assessment before treatment. It is further explained in Fig-1.

Table 4: significant difference between mean score of formative assessment after the treatment

\begin{tabular}{|c|c|c|c|c|c|c|}
\hline Sl. No & N & Mean & SD & SE & t-Value & P-Value \\
\hline Study group & 20 & 91.58 & 1.91 & 0.084 & 27.97 & 0.00 \\
\hline Control group & 20 & 67.94 & 3.82 & & & \\
\hline
\end{tabular}

Non-significant $(\mathrm{p}>0.05) \mathrm{df}=38$

table value of $t$ at $0.05=2.02$

Table -4 illustrates that calculated value of $t$ is found to be 27.97. It is statistically significant as it is greater than the critical value of $t$ at 0.05 level. Hence the hypotheses "There is no significant difference between the study group and the control group on the formative assessment after treatment" is rejected. It is clearly revealed that the students of the study group show excellent performance when compared to the students of the control group on the formative assessment after the treatment. It is further clarified in Fig -2.

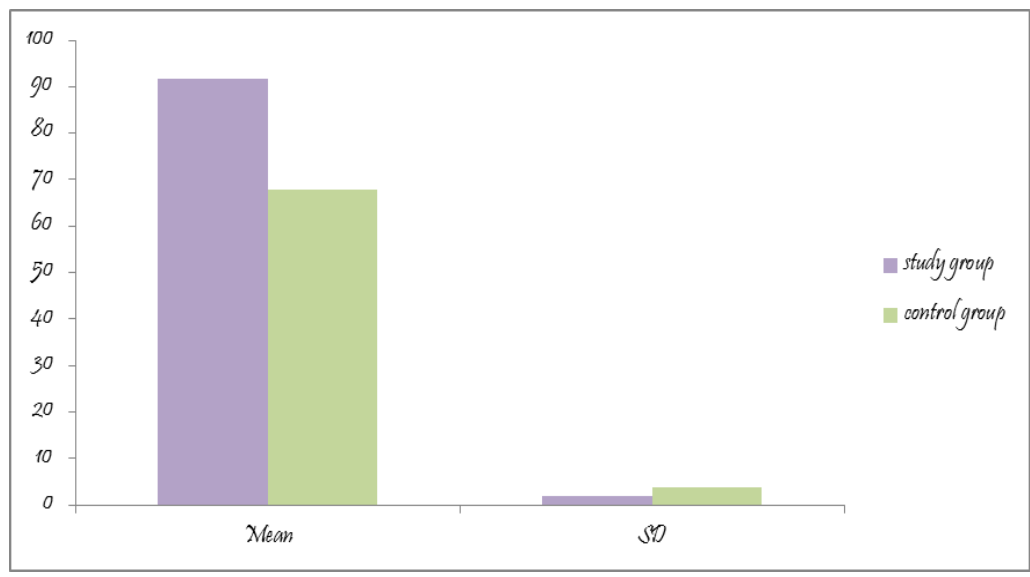

Figure 1: Mean difference between study and control group on formative assessment before the treatment

Table 5: significant difference between mean score of summative evaluation

\begin{tabular}{|c|c|c|c|c|c|c|}
\hline Sl. No & $\mathrm{N}$ & Mean & SD & SE & t-Value & P-Value \\
\hline Study group & 20 & 86.58 & 2.54 & 0.64 & 33.67 & 0.00 \\
\hline Control group & 20 & 65.30 & 1.95 & & & \\
\hline
\end{tabular}

Non-significant $(\mathrm{p}>0.05) \mathrm{df}=38$

table value of $t$ at $0.05=2.02$ 


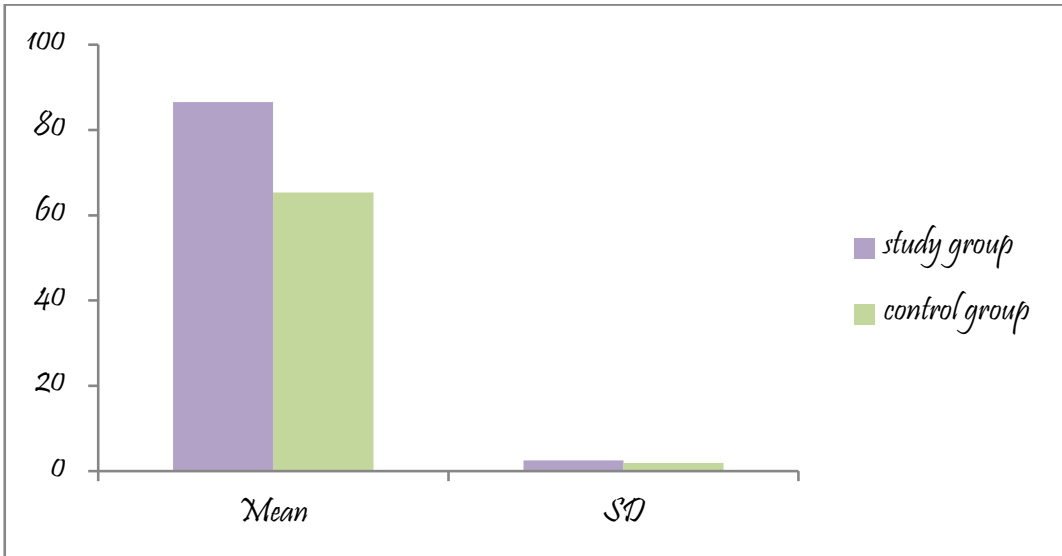

Figure 3: Mean difference between study group and control group on summative evaluation

Table- 5 indicates that the calculated t-value is found to be 83.07 and it is significantly greater than the table value of $t$ at 0.05 level. Hence the hypotheses "There is no significant difference between the study group and the control group on the formative assessment on retention test" is rejected. It explicitly depicts that the students of the study group show excellent academic performance as compared to the control group in summative evaluation (retention test) and further it is clarified in Fig 3.

\subsection{CONCLUSION}

The researcher after statistical analysis of data arrives at the following conclusion:

There is a significant positive impact of using experiential learning activities on the academic performance among the Senior Secondary school students. Experiential learning activities are very effective in raising the academic performance level of the students in Chemistry. Experiential learning activities are more effective in deep understanding of the concepts in Chemistry.

When students are exposed to experiential leaning activities they perform better when compared to the students of control group as individual attention is paid during the conceptual understanding. It also has a positive impact on the motivational level and satisfactory level among students.

In nutshell it can be concluded that the experiential learning activities have significant positive impact on the deep learning and conceptual understanding.

\subsection{RECOMMENDATIONS}

Most of the teachers are confronted with fact that merely providing information to students will not provide guarantee that it will internalize in a meaningful way. Experiential learning activities will internalize in a meaningful way and demonstrate the importance of experiential learning as a best pedagogical practice.

\section{SOURCES OF FUNDING}

This research received no specific grant from any funding agency in the public, commercial, or not-for-profit sectors.

\section{CONFLICT OF INTEREST}

The author have declared that no competing interests exist.

\section{ACKNOWLEDGMENT}

None. 
Evidence Based Learning: An Analysis of Impact of Experiential Learning on Attainment of Intended Specific Learning Outcome

\section{REFERENCES}

[1] Prashant Thote, Experiential Learning: Inclusive Art Education for Joyful Learning, Review of Research, Vol 8, Issue- 09, June 2019.

[2] Prashant Thote, Experiential Learning: Model for Teaching Science at Grade Nine, Research Magma, Vol-3, Issue -06, August - 2019.

[3] Prashant Thote, An Analysis of Impact of Evidence Based Learning on Academic Achievement of Students, International Journal of Research- Granthaalayah, Vol 8, Issue- 08, August 2020.

[4] Prashant Thote, Experiential Learning: An Analysis of Impact on Academic Achievement Among Students of Grade 12, International Journal of Research- Granthaalayah, Vol 8, Issue- 09, September 2020.

[5] Prashant Thote, Evidence Based Learning: An Analysis of Impact on Retention of Knowledge, International Journal of Research- Granthaalayah, Vol 8, Issue- 10, October 2020.

[6] Prashant Thote, Outcome Based Learning: An Analysis of Impact on Academic Achievement Among School Students, International Journal of Research- Granthaalayah, Vol 8, Issue- 11, November 2020.

[7] Prashant Thote, Evidence Based Learning: An Analysis of Impact of Remedial Teaching on Conceptual Understanding, International Journal of Research- Granthaalayah, Vol 8, Issue- 12, December 2020. 